\title{
Apollo's Challenge as a Driving Force in Education
}

\author{
Nikolay N. Gubanov \\ Bauman Moscow State Technical University \\ 5/1, 2nd Baumankaya Str. \\ Moscow, Russia 105005 \\ E-mail: gubanovnn@mail.ru
}

\author{
Nikolay I. Gubanov \\ Tyumen State Medical University \\ 54 Odesskaya Str. \\ Tyumen, Russia 625023 \\ E-mail: gubanov48@mail.ru
}

\author{
Lyudmila Rokotyanskaya \\ Bauman Moscow State Technical University \\ 5/1, 2nd Baumankaya Str. \\ Moscow, Russia 105005 \\ E-mail: lo_rokotyanskaya@rambler.ru
}

\begin{abstract}
The analysis of the historical development of education reveals one of the main driving forces in its growth. In order to describe it, we introduce and research a new social and philosophical concept: Apollo's challenge. This essence of the challenge is that society must resolve periodically emerging contradictions between the demands of growing rational knowledge and the social and cultural conditions for this knowledge existence and development. It is shown that in the case when society creates social provisions for new rational knowledge appropriate for the needs of developing this knowledge, the latter can continue its advanced development. This development is determined by incremental rational knowledge, realized in various spheres of society, determines its progressive development.
\end{abstract}

Keywords-Apollo's challenge; mentality of education executives; university tradition; education innovations; education potential of society; social support system of knowledge acquisition

\section{INTRODUCTION}

The identification of factors that stimulate education is an important objective of the social and human sciences. A.D. Toynbee's "challenge-and-response" model became very popular among social scientists after he first introduced it in A Study of History in 1961. We use this model's heuristics when considering the development of education. Toynbee believed that challenge encourages growth. The answer to the challenge is to solve the issue facing the society, thus transferring itself to a higher and more perfect state in terms of structure complexity. Lack of challenges means that there is no incentive for growth and development [1]. The answer to a challenge is the nodal point of the history of a given society. By giving an inappropriate, weak answer, it will stagnate, degrade or even perish.

Periodically arising anthropogenic crises that create new historical challenges are of great interest for analysis. The following pattern can be established: when the changes caused by the crisis in the mass mentality are adequate to the challenge, the crisis can be overcome, and the society rises to a higher level of development. When the mass way of thinking does not change accordingly, the society leaves the arena of history. By mentality we understand the set of socio-psychological characteristics of an individual or group subject. These features determine the style of thinking, the specifics of perception and the direction of activities [2]. This article is devoted to the explication of an important challenge to the social environment, discovered by one of the authors of this article earlier and named "Apollo's challenge" [3].

\section{THE ESSENCE OF APOLLO's CHALLENGE}

The essence of this challenge is that from time to time every society faces an urgent contradiction between the accumulating rational knowledge with its internal logic and the current social cultural conditions and further development. The concept received its name by analogy with Toynbee's Poseydon's challenge (challenge of the sea). Apollo symbolizes rational knowledge. Rational as opposed to irrational is represented by the logical, systematized knowledge obtained by observation and logical reasoning in accordance with the principle of sufficient reason without manipulation, blackmail, suggestion, authority, or faith. It is characterized by the total exclusion of mythological, magical and other similar beliefs based on supernatural [4]. Rational knowledge is based on facts: reliable phenomena that are consistently repeated via mass observation or experiment [5]. The number of reasonable features in rational knowledge prevails over the number of unreasonable ones, and this prevalence increases with time. The largest part of rational knowledge is science, the most authoritative type of knowledge, with its strict justification and verification criteria. The second most rational field of knowledge appears to be philosophy. Elements of rational knowledge are also present in everyday knowledge, ethics, art, politics, to a small extent in theology when the latter employs logical reasoning.

Response to Apollo's challenge can be considered successful (appropriate or strong), when the growing rational 
knowledge is supported by social mechanisms, which address the requirements inherent to the development of this knowledge. Then knowledge will grow, become more complicated and deepen to the extent until its content will again require stronger support because of the emerging contradiction between itself and social conditions. This will be a transition to a new round of Apollo challenge. New components of rational knowledge ensure the progress of society by being objectified in its various spheres. If a society is unable to generate such a response, rational knowledge does not grow and is unable to develop its cognitive potential and the praxeological potential that it generates. A society with a deficit of rational ideas in a certain sphere will experience a roll back in the performance in this sphere. After some time, Apollo's challenge can reappear and the society will gain a new opportunity for response respond. However, the invaluable time in the competition of civilizations will have already been lost. A very strong response is required, if this society strives to become level with advanced civilizations.

We distinguish the following components of the knowledge support mechanisms in the society:

- Composition, quantity, and functions of knowledge actors: innovators generating ideas; transmitters and retransmitters of information; people regulating production and reproduction of knowledge, people determining which knowledge will receive social resource and which will not; people who will evaluate the benefits of the knowledge being created.

- Public status of knowledge actors: their social status, size and sources of their income, government support [6];

- Organizational and institutional knowledge base: what public (state and private) institutions are engaged in the production and reproduction of knowledge, what is the degree of their autonomy and independence from other societal institutions, who finances and controls them;

\section{- Facilities and resources of science and education}

Joint development of social relations and culture, i.e. sociocultural dynamics of society, which is initiated by Apollo's challenge, can be described by interpreting the societal responses to historical challenges as changes in mentality that precede subsequent social transformations [7]. The innovators' mentality produces new components of rational knowledge. These can be new knowledge, new interpretations of already existing knowledge, new approaches to the study of natural and social reality, new forms of organization of the education process, new teaching methods, new programs for the rationalization of any aspects of the society. Innovative cultural forms come into conflict with the existing societal conditions and demand social resources to be extensively implemented. This is Apollo's challenge. A strong response on the part of the society in this situation is to find such a solution that would provide innovative knowledge with appropriate social support. The response is usually generated by culture leaders or ruling establishment. This is not about the innovators' consciousness, but about their mentality, because mentality as part of their inner world determines the novelty, originality and direction of any activity. When the society makes an appropriate response, it means that the social transformation program, which initially emerged as a mental feature of innovators, is realized in the society. This creates more favorable conditions for the development of rational knowledge. An appropriate response can be in the launch of a social institution that did not exist before, an increase in the number of subjects of knowledge, an increase in their standing in the society, stronger financial support, and so on.

An important aspect of Apollo's challenge model is the contradiction between the level of education of the country leaders and the increasingly complex social reality that gives rise to new challenges in management. The problem of increasing the level of the rulers' education has not been solved yet. V.A. Nehamkin sees the solution in a special Institute of Universal Education, which will provide future candidates to the ruling establishment, including presidency, with comprehensive fundamental knowledge $[8,9]$.

\section{RESPONSES TO APOLLO'S CHALLENGE IN THE HISTORY OF EDUCATION}

Let us consider some of the past responses to Apollo's challenge. A very strong response was given by the Greeks and its name - "myth to logos transition"- is in tune with our concept. The outcome was the rational knowledge branching out from mythology, whose constraints hampered the development of rational thought. The important achievements of the Greek response became the following components of the social support of knowledge: 1) emergence of special bearers and multipliers of this knowledge - the first philosophers whose attitude to truth was principally different: not the result of dogmatic faith supported by authority, but the result of rational evidence based on substantiation of logical arguments and facts; 2) formation of schools of thought launching a continuous tradition of thinkers studying each other's ideas, public disputes, and mutual comments on philosophical works; 3) awarding high social stature to those engaged in contemplation and theorizing and, as a consequence, an increasingly large number of free citizens being involved, which had a beneficial effect on their occupation.

Elements of rational knowledge were present in the Ancient East, and in some cases, the success of the ancient Eastern thought was significant. However, the ancient Eastern knowledge was not rational in the full sense of the word and did not create the first historic form of science: mathematics. The ancient Eastern mentality did not develop the cognitive methods that would be based on discursive reasoning, and rather than dogmas, recipes and divinations. The Greek mentality, however, generated innovative projects in response to Apollo's challenge forming the basis for new epistemological and social structures that determined the design of science as such. Among the components of the new epistemological standard developed by the Greek thinking, we particularly note the following: considering a subject in a general ("pure") form; generating universal evidence; the 
universal principle of criticism and the search for a better justification; the ideology of contemplation and the abstractspeculative-artistic perception of reality; free play of the mind with an intellectual subject, which spread and strengthened idealization. The Greeks drew a clear boundary between rational and irrational, the latter being excluded from philosophy and emerging sciences. The logical reasoning system formed by philosophers influenced politics and stimulated the development of democracy.

Let us pass on to the Middle Ages. The starting point will be $528 \mathrm{AD}$ when Justinian I closed down all schools of philosophy, which he considered "the last strongholds of paganism." Athenian philosophers were expelled, and Athens became a sleepy provincial city. Most of the philosophers - the main bearers of rational knowledge moved to the East. The rational knowledge rejected in the West found favorable conditions for further development in Iran, Iraq, Syria, and Egypt free from the Roman rule. There were two different responses to Apollo's challenge. In the West, Apollo's challenge manifested itself in an irreconcilable confrontation between philosophical and religious knowledge. Justinian I, eradicating paganism, gave a wrong response. As a result, a significant part of the Greek scientific and philosophical knowledge in Europe was lost. However, the Greek rationality was transferred to another culture. The Eastern elite was able to give an appropriate response to Apollo's challenge determined by the need to assimilate and creatively develop the Hellenistic heritage. Because of this, there emerged an Arabic-language intellectual tradition that dominated the world almost until the first scientific revolution.

Khosrow I (501-579), the shahan shah of Persia, welcomed the Greek philosophers and founded a scientific school with emphasis on philosophy and medicine. The works of Aristotle, Galen, and Hippocrates were translated into Persian. Harun al-Rashid (763-809) established a university and a library in Baghdad. He sent people to the West to search for the Greek written works. Al-Ma'mun (786-833) included scientists into his administration, founded an observatory and the "House of Wisdom" in Baghdad, which brought together the most prominent scientists in the caliphate. The Arabs assimilated not only the Greek culture, but the Indian and Chinese cultures as well. A mathematician Al-Khwarizmi was the first to use Indian numerals, which are known as Arabic numerals now. Starting from the 10th century, parchment was replaced with paper. In the Islamic world there were hundreds of libraries. Al-Raziwas the first to start treating chickenpox and measles. Avicenna synthesized the Greek and Arabic medicine, IbnYulas became the founder of trigonometry, Ibn al-Haytham was the first to produce magnifying crystal lenses.

For a long time Arabs held the leading position in astronomy, optics, medicine, and mathematics. The reason for this, as was shown above, was an appropriate response to Apollo's challenge. The main components of this response are encouragement and funding of scientists by the ruling establishment, founding libraries and educational institutions, securing links with representatives of other cultures, raising the prestige of intellectual efforts. Another component of
Apollo's response was equally important. It concerned the relationship between rational knowledge (philosophy and science) and religion. Al-Ghazali (1058-1111), as a Muslim, rejected Avicenna's philosophy and argued that if philosophical knowledge did not conform to the Quran, the former was fallacious. A similar conflict emerged in Europe. An adequate response to the religious attack was given by Ibn Rushd (1126-98). He substantiated the idea of interpreting the corresponding fragments in the Quran: when a direct interpretation of the provisions in the Quran seems to contradict the provisions of philosophy and science (reason), then the corresponding surahs must be interpreted allegorically or metaphorically. Therefore, there is no contradiction between the Quran and philosophy. Thus, the thinker secured philosophy and science from religious criticism and possible inhibition of rational cognition. As a result of appropriate responses to Apollo's challenge, the Arabic East was for more than six centuries superior to the West in science and technology. But what was the reason that prevented the Arabic culture from giving rise to modern science, with the latter emerging in Europe in the 16th and 17 th centuries? We believe that this happened as a result of changes in the content of Apollo's challenge-and-response.

The strong response that the Arabs had been giving to the religious component of Apollo's challenge weakened with time. Perhaps this was due to the fact that there were no philosophers equal in their intellectual level to Ibn Rushd, who could reconcile the growing rational knowledge with religious dogmas. The criticism of Arab scholars in the religious circles became more intensive. From the standpoint of religion, a significant part of the scientific fields were interpreted as useless undermining the picture of the world presented in the Quran.

Another component of the answer, inadequate for the needs of the growing knowledge, was the absence of a basis for rational knowledge. The madrasas served as the main center of education. Their task was to study the "Islamic sciences", the Quran, the life of the Prophet and the Islamic law. And "foreign science" was not necessarily taught. There was no formation and recognition of guilds and corporations. There was no legal registration of professional groups of teachers and students. Their independent development was difficult. Autonomous, self-governing academic institutions of the European type have not emerged. The inability of the Arab elite to include knowledge of a rational type in the structure of the societal institutions turned out to be a weak response to Apollo's challenge. Gunnar Skirbekk and Nils Gilje rightly note that the most important reason for the stagnation of the Arab science in the 14th century was that the Arab world had never been able to create independent universities that would have been tolerated supported by both secular and religious authorities [10].

Let's return to the situation in Europe. When schools of philosophy were closed down, some of the ancient learning was preserved in the monasteries. For a few centuries after this, monasteries were the only centers where formal training was provided. Teaching was conducted in Latin. The Greek language was forgotten, and the access to the ancient rationalism was lost. Prior to this, Arabs had translated the 
main works of Ancient authors. Europeans got acquainted with these translations only in the 10th century. The scientist who widely known Europe was Ibn Rushd. He wrote commentaries to Plato and Aristotle's works and influenced Thomas Aquinas. The concepts of harmony between faith and reason could to some extent be borrowed from the works of Ibn Rushd by Aquinas. So, the mental feature that emerged in the Arabic world as a response to Apollo's challenge later reappeared in Europe in the teachings of Aquinas and played a role in preparing a strong response of the Europeans to Apollo's challenge.

The onset of the European science took place during the reign of Charlemagne (768-824). In his empire Apollo's challenge manifested itself in the need to fill the emerging intellectual vacuum. The empire lacked an administrative structure that could keep strong kingdoms together. To form an effective education system became a pressing task. The ruling establishment responded to Apollo's challenge with the Carolingian Renaissance. The emperor sought to restore the lost ancient wisdom. In Aachen, the capital, he founded the Palatine school, which became an important culture center. He also opened monasteries and cathedrals, which would later become the bases for the first universities. For a long time the Palatine school was headed by Alcuin, who sought to revive the Greek idea of seven arts (artes liberales) which should be studied by free people. There were two groups of arts: 1) trivium, which included dialectics (logic), rhetoric, grammar; 2) quadrivium, which included music, astronomy, arithmetic, geometry. Universities to be created in Europe in the 12th century would also use the idea of seven arts. The Carolingian period is when the term scolasticus (scholastic) appeared (from Latinschola- school). This was the name for the quadrivium and trivium teachers. Later the name was applied to all teachers, while the disciplines studied in the medieval schools came to be called scholastic [11,12].

If we compare the Arabic and the European responses to Apollo's challenge, we can conclude that the Arabic response was stronger than the European one in three respects: 1) the Arabic response began earlier; 2) in Europe, the trivium disciplines became popular; missionaries, priests and monks were taught grammar, dialectics and rhetoric, and disciplines from were considered unnecessary, while in the Arab world, quadrivium disciplines intensively developed; 3) the scope of the Arabic response was greater in comparison with the Europian one. All this led to the centuries-old scientific and technical superiority of the East. There is a similarity in the educational institutions distribution: madrassas in the East, monasteries and cathedral schools in Europe. Initially, organization of education and knowledge in the East was more effective than in the West. When the inherent logic of the rational knowledge development required a new incarnation in the social structure (another round of Apollo's challenge), European schools were able to be transform themselves into universities, which were autonomous in their search for the truth, while the eastern madrassas were to become "graves" of eastern science.

\section{UNIVERSITIES AS AN APPROPRIATE RESPONSE TO APOLLO's CHALLENGE}

Dating back to the XII century, universities were an intellectual innovation. In the Middle Ages, the term universitas was used by lawyers to refer to any union of people [13]. An organization created with the focus on cognitive activities was first called universitas stadium, so that it could be distinguished from other institutions. Later it became known as stadium generale - the general school. The word generale emphasized its difference from local and local schools. The titles and degrees awarded in the stadium generale were recognized by all other general schools of Christian Europe, and the holders of the corresponding titles and degrees could teach at these schools. This circumstance was an important part of the response to Apollo's challenge. There was an urgent need to unify the principles at the heart of the educational process. Without such unification, the subsequent development of knowledge would be difficult. The response to this challenge was given by the educational and administrative elite of that era. Thanks to the innovation of studium generale, educational institutions were integrated on the basis of uniform standards. In the $15^{\text {th }}$ century the term universitas replaced stadium generale.

Growing rational knowledge also required a greater number of actors to enable its development and dissemination. The response to this challenge was university corporations. All first universities were located in cities. The city authorities were interested in educated people, and in control over education. For cities, there was obvious economic benefit from universities: increase in tax collections and income for homeowners. The growth of universities was also determined by the social benefits their graduates received thanks to good employment opportunities. For example, there was a serious shortage of lawyers. Around the year 1200 there were about 50 thousand people in Paris; one tenth of them was students.

As was noted above, through the implementation of the stadium generale concept enabled a certain integration of educational institutions on the basis of common standards. But the integration happened in terms of form (ways of conducting classes, organization of the educational process, knowledge assessment, degrees awarded, etc.). Along with this, there was a need for differentiation in terms of content: educational institutions were required that would specialize in certain sciences for more profound understanding. In response to this, universities separated and began to specialize in certain subjects. Many students, having started their studies at one university, could continue their education elsewhere. Goliards, or wandering students, were a spectacular feature of the Middle Ages. They led a hard life wandering through Europe. Goliards are the authors of the students' song Gaudeamus (Latin for "So let us rejoice").

For rational knowledge to develop successfully, a special institutional basis is required to ensure the independence and autonomy of educational institutions. The West gave an appropriate response to this component of Apollo's challenge. Apparently, the response was created by a broad mass of university corporations members [14]. To defend 
their interests, students used an effective method of threating the city community to move to another city. The most important event in the process of the universities gaining their autonomy was the publication in 1231 of Bulle Parens scientiarum (bulls: parental science) by Pope Gregory IX. Before its release, there were numerous boycotts and riots among students in Paris and other cities. This edict granted the universities the right to develop and establish their statutes, curricula and exam requirements, which ensured equal treatment of examination certificates from different institutions.

\section{CONCLUSION}

In our opinion, the above components of the response to Apollo's challenge are some of the key factors that stimulate the development of education. Russia is currently going through an active phase of the response to Apollo's challenge. One of the important components of this response is Russia's participation in the Bologna process [15]. This participation provokes intensive discussions. We believe the Bologna system to be similar to the idea of stadium generale, which we interpreted as a strong response. Other important components of Apollo's challenge facing the modern Russian education system are the optimization of universities and their branches, effective incentive of teachers' effort, the introduction of objective criteria for research assessment, promotion of academy, industry, business and $R \& D$ cooperation.

\section{REFERENCES}

[1] Toynbee A.J. A study of history. Oxford University. 1934-1961.

[2] Gubanov N.I., Gubanov N.N. Mentality: the nature and functioning in society // Voprosy filosofii. 2013. № 2. P. 22-32.

[3] Gubanov N.N. Apollo's challenge as a stimulus for the education development // Alma mater (Vestnik vysshey shkoly). 2014. № 5. P. 19-23.

[4] Lazarev F.V., Lebedev S.A. The Philosophical Reflex: Essence, Form, Types // Voprosy filosofii. 2016. № 6. P. 15-28.

[5] Gubanov N.I., Gubanov N.N. Course of lectures in philosophy of science // Herald of the Russian Academy of Sciences. 2015. V. 85. № 10. P. 946-948. DOI: 10.7868/S0869587315100059

[6] Gubanov N.I., Gubanov N.N. The role of mentality in the development of society: sociocultural hypothesis // Vestnik slavianskikh kultur-bulletin of slavic cultures-scientific and informational journal. 2017. Vol. 43. № 1. P. 38-51.

[7] Gubanov N.I., Gubanov N.N. Global mentality as a pre-condition of civilizations' conflict prevention // Sotsiologicheskie issledovaniya. 2011. № 4. P. 51-58.

[8] Nekhamkin V.A. A counterfactual Challenge of the Past: Ways of Negotiation // Herald of the Russian Academy of Sciences. 2017. Vol 87. Issue 2. P. 191-198. DOI: 10.1134/S1019331617020046;

[9] Nekhamkin V.A. Role of the national leader's education in the process of historical development // Sociology of education. 2012. № 2. P. 82-97.

[10] Gilje N., Skirbekk G. A. History of Western Thought: From Ancient Greece to the Twentieth Century. Routledge. 2013.

[11] Ivleva M.L., IvlevV.Yu.Principal approaches of modern psychology to constructing giftedness // "Proceedings of the 2017 2nd International Conference on Contemporary Education, Social Sciences and Humanities". (ICCESSH 2017). Part of the series ASSEHR. Moscow, Russia. V.124. P.1176-1180.
[12] IvlevV.Yu., Ivleva M.L. Peculiarities of Aristotelian scholastic logic // "Proceedings of the 2017 2nd International Conference on Contemporary Education, Social Sciences and Humanities". (ICCESSH 2017). Part of the ASSEHR series. Moscow, Russia. P.9195.

[13] Van Haaske L.A. Formation of the universal corporations and their regional characteristics in Europe of the high middle ages // Vestnik of Sholokhov Moscow State University for the Humanities: History and Political Science Series. 2012. № 3. P. 34-41.

[14] Gubanov N.N. Education and mentality as part of the driving forces in the development of society // Sociology of education. 2010. No 1. P. 22-29.

[15] Suzdaleva T.R. Migratory processes in the context of geopolitics // Vestnik Tomskogo gosudarstvennogo universiteta-Filosofiyasotsiologiya-politologiya-Tomsk state university journal of philosophy sociology and political science. 2016. № 3 (36). P. 237 244. DOI: $10.17223 / 1998863 X / 35 / 25$. 